\title{
Performance Evaluation of Conventional Hot Mix and Porous Asphalt Under Accelerated Loading
}

\author{
Ludfi Djakfar ${ }^{1,}$, Harimurti ${ }^{1}$, Yulvi Zaika ${ }^{1}$, and Ketut Sugiarto ${ }^{1}$ \\ ${ }^{1}$ Department of Civil Engineering, Universitas Brawijaya, Jl. M.T. Haryono 167 Malang, Indonesia
}

\begin{abstract}
The purpose of the study is to evaluate and compare the performance of conventional hot mix asphalt and porous hot mix asphalt under accelerated loading. To achieve the objective, a test section was constructed and tested with a loading device previously developed. The pavement material conforms to the Indonesian Directorate General of Highway. While the porous surface conforms to the Australian standard for asphalt porous. The thickness of the test section was prepared to simulate the real condition of the pavement structure. The load, equivalent to the standard $8,160 \mathrm{~kg}$ axle load was applied for 1,000 passes. For every 100 passes, stresses and deformation were recorded. The result shows that there is some consistency between theory and field results in terms of stresses and deformation. Conventional surface course seems to perform better in deformation/rutting. Future research should be directed to improve the performance of the device and also the performance of the porous asphalt.
\end{abstract}

\section{Introduction}

As a country positioned in the equatorial lines, Indonesia experiences heavy rain almost 6 months in a year. This condition has caused some water to present in the pavement surface, which has some detrimental effect either to the pavement itself or to the road users since it may cause accidents due to hydroplaning. The majority of the road in Indonesia was constructed using conventional hot mix asphalt (HMA). While many studies and experience showed that porous HMA has satisfactory performance in dealing with splash water and hydroplaning, the Highway Agency seems to be unconvinced with these facts. Very few porous HMA have ever been constructed.

Many researches have been conducted to evaluate the performance of the porous HMA. Most of the efforts, however, are still in lab-based evaluation. Therefore, research should be directed to evaluate the performance of pavement using field data. Previous efforts have been conducted. Louisiana Transportation Research Center has constructed an Accelerate Loading Facilities (ALF) in order to evaluate the performance of several types of pavement materials [1]. Bonaquist et al. [2] used the ALF to evaluate the effects of tire pressure on flexible pavement response and performance. Sebaaly et al. [3] used data from previous ALF research to evaluate relationships between surface cracking and the structural capacity

*Corresponding author: Ldjakfar@ub.ac.id 
of both thin and thick pavements. Kadar [4] used the ALF test results to assess the relative performance of a variety of asphalt surface types for pavement rehabilitation. JohnsonClark et al. [5] employed the ALF to investigate the effectiveness of a geotextile reinforced seal between the subgrade and gravel layers to rehabilitate low volume roads.

Several researchers have also developed and utilized accelerated pavement testing to investigate the performance of some pavement materials. Tang et al [6] used Model Mobile Load Simulator (MMLS3) to investigate the use of geogrids for subgrade stabilization in flexible pavements. Al Qadi et al. [7] investigated the effect of various tire configurations on Geogrid-reinforced low-volume flexible pavement using the mobile Accelerated Testing

Loading Assembly (ATLAS) housed at University of Illinois at Urbana-Champaign.

One hindrance of using existing equipment is its cost and its availability, which may become the main reason for the highway department particularly in developing countries to hesitate to use it. Therefore, simpler and modest equipment need to be developed for the purpose of mobile accelerated testing of pavement.

\section{Objective of study}

The objective of the study is to evaluate the performance of conventional and porous asphalt when subjected to accelerated loading.

\section{Methods}

To achieve the objective, two test sections: (1) conventional and (2) porous sections were constructed and tested. Fig. 1 shows the scheme and dimension of the test section. The thickness of base and subbase section was prepared simulating the common dimension encountered in the field, while the thickness of the surface was $3 \mathrm{~cm}$. The reason of using 3 $\mathrm{cm}$ thick of surface material in the test section is to ensure that the strain gauge installed beneath each layer can respond and read the signal caused of the applied load. Since this is the preliminary testing, the researchers would like to make sure that the strain gauges could function as intended, by using a thinner surface course.

\subsection{Materials}

Materials used to construct the test section consist of Class A for base and Class B for subbase and conform to the Indonesian Directorate General of Highway (IDGH) Specifications. Tables 1 and 2 present the material characteristics for base and surface course. The conventional HMA surface course was designed to conform to the Specification requirement of the IDGH Specs, while porous HMA surface course was designed based on porous asphalt specification with $8 \%$ Gilsonite additive, since previous research [8] showed that adding the Gilsonite additive increases the stability up to $800 \mathrm{~kg}$ without significantly reducing its permeability capability, as shown in Table 2 . The pavement was constructed on the sandy soil subgrade with $10 \%$ CBR. Fig.2 presents the test section construction. 


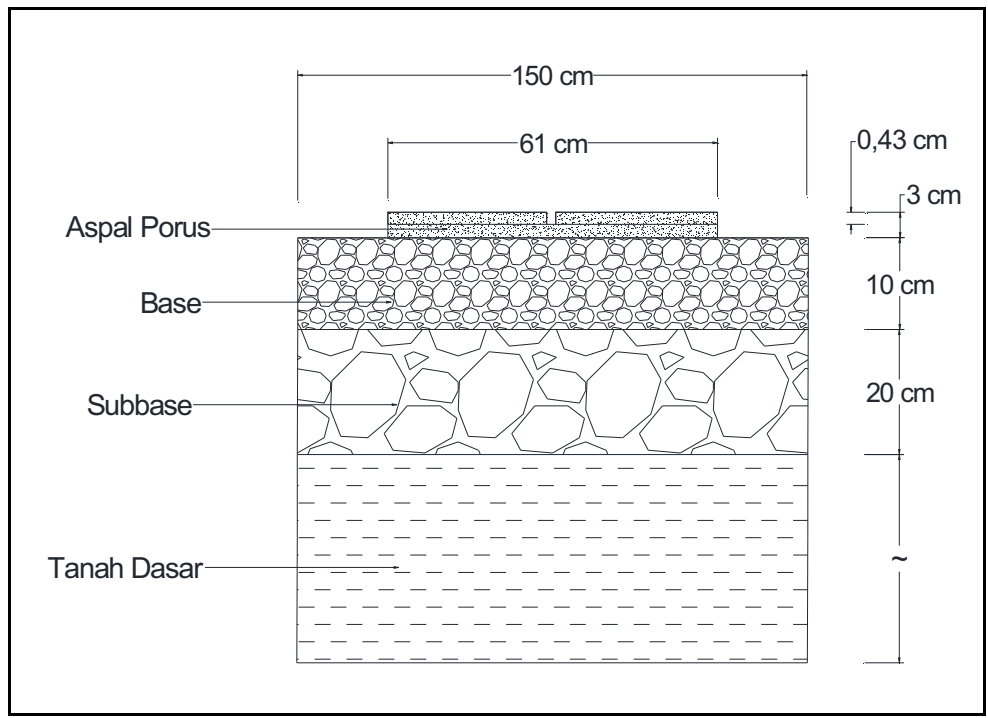

Fig. 1. Dimension of pavement structure constructed at the test section

Table 1. Unit weight and CBR of the subgrade, base and subbase materials

\begin{tabular}{|c|c|c|c|}
\hline \multirow{2}{*}{ Layer } & \multicolumn{2}{|c|}{ Unit Weight $\left(\mathrm{gr} / \mathrm{cm}^{3}\right)$} & \multirow{2}{*}{ CBR $(\%)$} \\
\hline & Laboratory & Field & \\
\hline Subbase & 1.80 & 1.83 & 75 \\
\hline Base & 1.79 & 1.69 & 82 \\
\hline Subgrade & 1.57 & & 15 \\
\hline
\end{tabular}

Table 2. Marshall characteristics of the surface course

\begin{tabular}{lll}
\hline $\begin{array}{l}\text { Marshall } \\
\text { Characteristics }\end{array}$ & Conventional HMA & Porous HMA \\
\hline VIM & $3 \%$ & $8,1 \%$ \\
Stability & $1500 \mathrm{~kg}$ & $805 \mathrm{~kg}$ \\
Flow & $2,5 \mathrm{~mm}$ & $3,8 \mathrm{~mm}$ \\
MQ & $550 \mathrm{~kg} / \mathrm{mm}$ & $219 \mathrm{~kg} / \mathrm{mm}$ \\
\hline
\end{tabular}
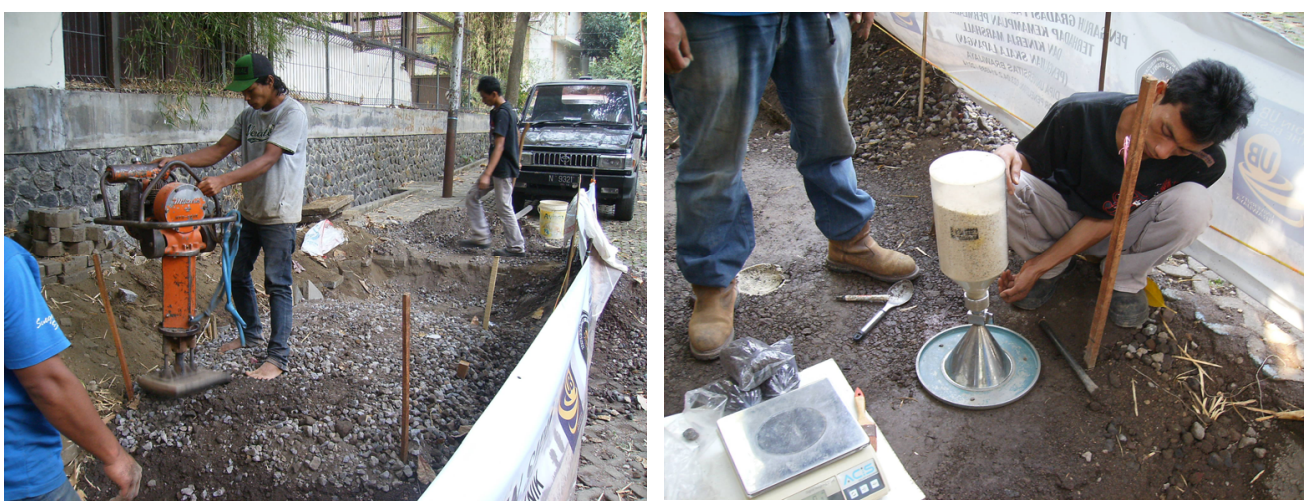

Fig. 2. Construction of test section 


\subsection{Installation of the strain gauge}

To record the strain and stress occurring in the pavement due to load, a set of strain gauge was installed between the surface and base course as shown in Fig. 3, and spaced at $40 \mathrm{~cm}$ as shown in Fig. 3b.

\subsection{Loading device}

To simulate the traffic load, a loading device was developed as shown in Fig. 4. The device can run at $2.7 \mathrm{~km} / \mathrm{h}$. The model test tire footprint is $1 \mathrm{~cm} \mathrm{x} 1 \mathrm{~cm}$ while the applied load is $17 \mathrm{~kg}$. It is based on the assumption that the model should produce stress on the pavement similar with that produced by standard axle load $(8160 \mathrm{~kg})$ and the truck tire footprint $(11 \mathrm{x}$ $11 \mathrm{~cm})$. The first set of the research using this device has been published elsewhere [9].

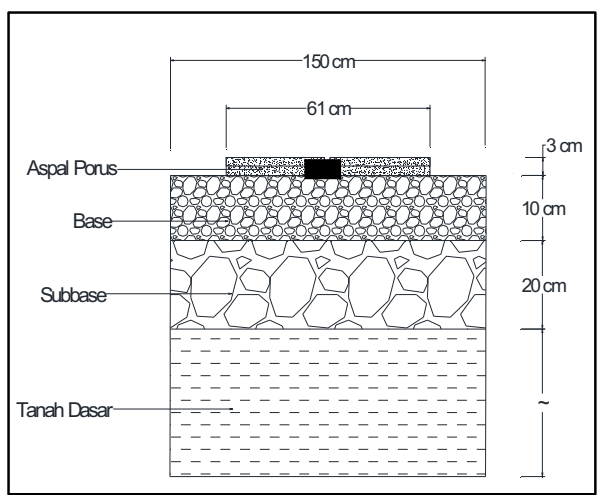

(a)

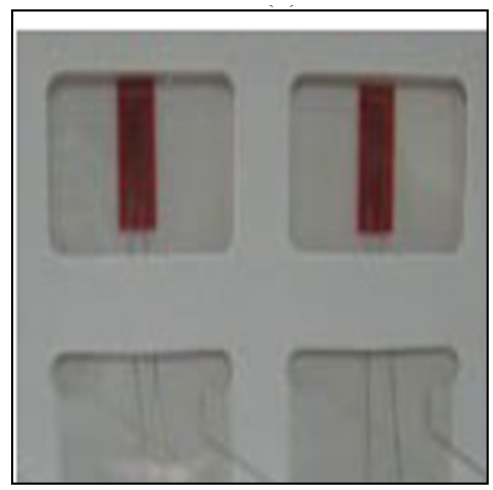

(c)

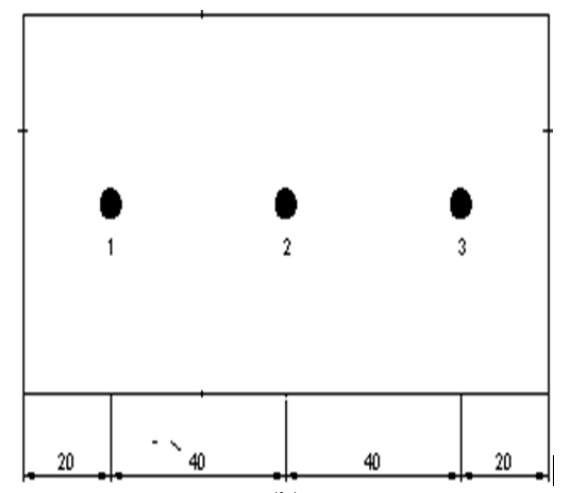

(b)

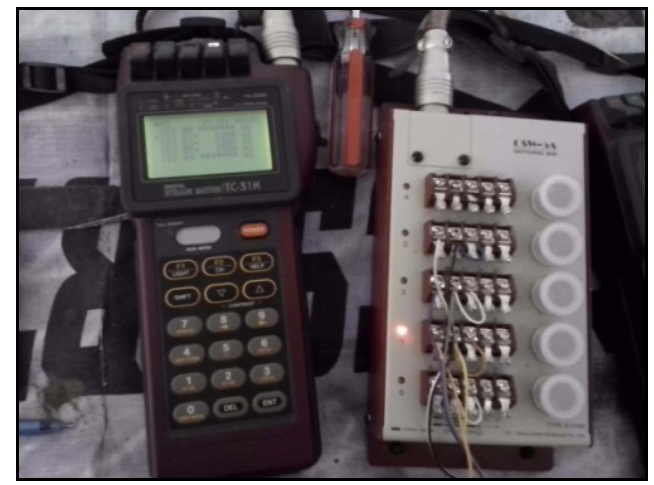

(d)

Fig. 3. Installation of strain gauge. (a) cross section, (b) location of strain gauge, (c) type of strain gauge, (d) strain meter 


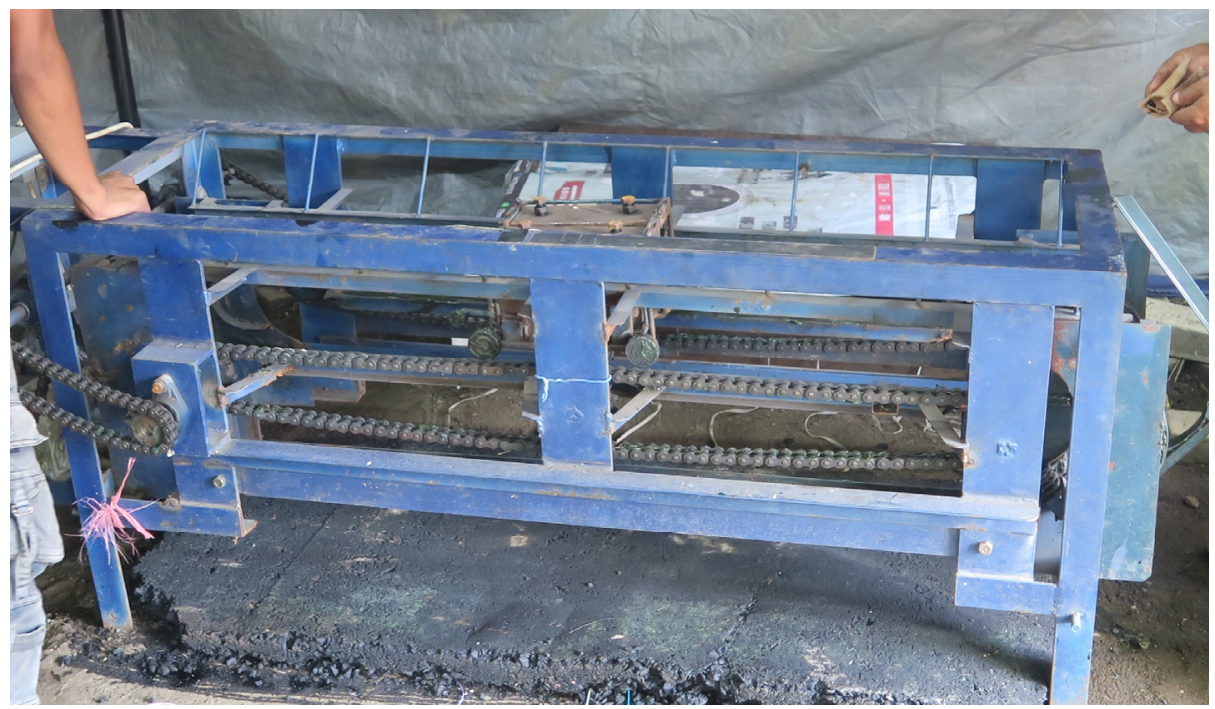

Fig. 4. Loading device

\section{Results}

Fig. 5 and 6 present the stresses recorded below the surface course for conventional and porous HMA, respectively. The measurement was made when the moving load was on top of the strain gauge. Fig. 7 present the deformation recorded at the surface course.

Fig. 5 shows that the stress recorded at the $3 \mathrm{~cm}, 5 \mathrm{~cm}$, and $20 \mathrm{~cm}$ from the surface generally shows constant over time, although at some it tends to be lower. It can therefore be interpreted that with constant loading, the stress induced by the load remains constant in the pavement structure. It also shows the relative consistency of the loading and recording device.

The test result also shows some peak at stress recorded at every 50 passes. At every 50 passes, the loading was stopped temporarily to allow the deformation readings. The researchers also suspected that this peak was due to the nature of the pavement material elasticity, where after the load, it needs some time to get back to its original position.

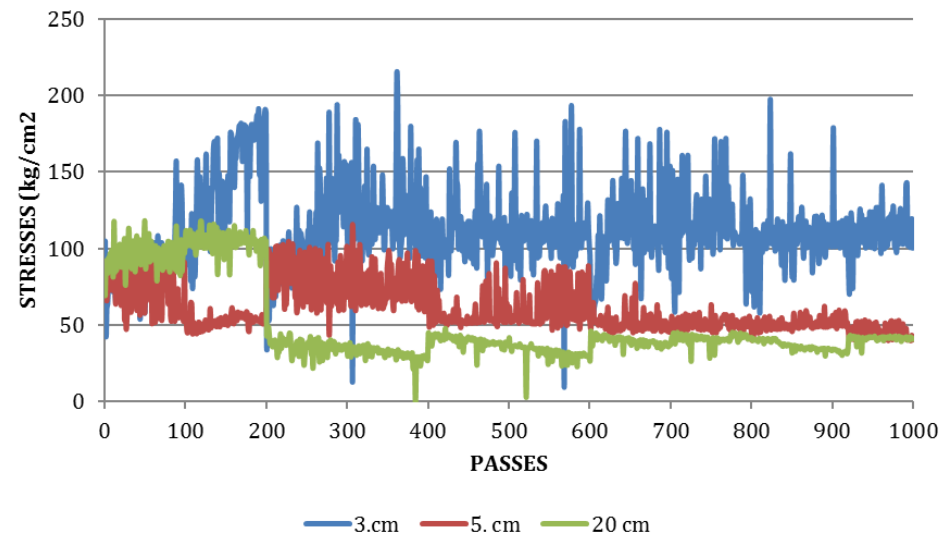

Fig. 5. Stress vs passes for conventional HMA course 


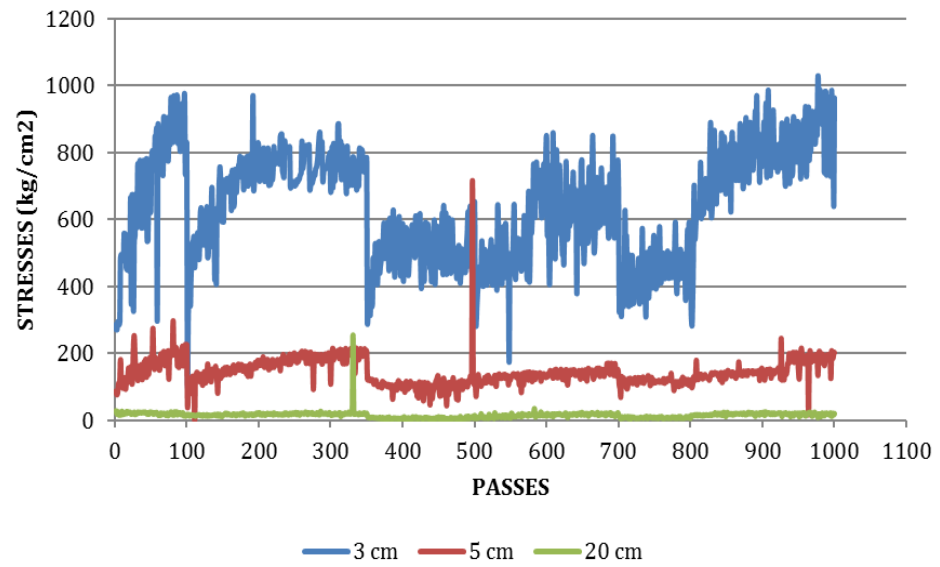

Fig. 6. Stress vs passes for porous HMA course

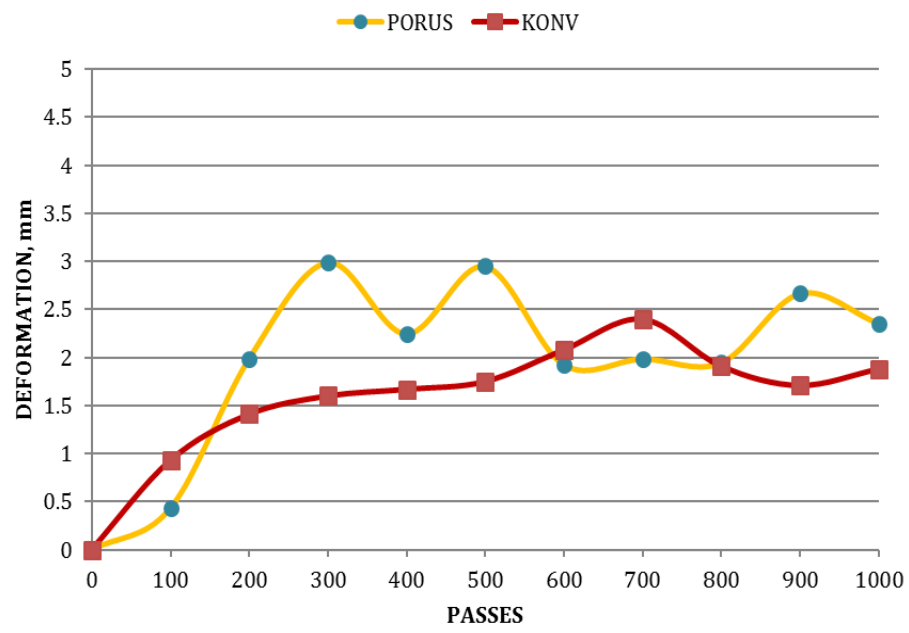

Fig. 7. Deformation comparison between conventional and porous HMA

Fig. 7 shows the deformation recorded from the test section. It is recorded every 100 passes. The figure shows that the conventional HMA structure tends to rut lesser than that of porous structure. It is due to the structure of the conventional HMA has less void compared to porous HMA, which may cause the structure has better rutting performance.

\section{Conclusion and recommendation}

Based on the results from the test section, the following conclusion can be drawn:

i) At low passes (up to 1000 passes) the equipment developed in this research has shown a good result in evaluating the stress and deformation occurred in the pavement.

ii) The stress occurring in both conventional and porous pavement tends to constant at the constant loading. 
iii) The porous structure has slightly lower performance compared to conventional in terms of rutting.

iv) The result presented in this paper is a preliminary one, further enhancement of the equipment and longer testing period is needed in order to better simulate the field behavior of pavement.

\section{References}

[1] L. Djakfar, F.L. Roberts, Performance Prediction of Louisiana ALF Test Sections, Transportation Research Record 1597, Transportation Research Board,Washington, (2000)

[2] R. Bonaquist, R. Surdahl and W. Mogawer, Effect of Tire Pressure on Flexible Pavement Response and Performance, Transportation Research Record 1227, Transportation Research Board, Washington, 97-106 (1989)

[3] P. Sebaaly, N. Tabatabaee, R. Bonaquist and D. Anderson, Evaluating Structural Damage of Flexible Pavements Using Cracking and Falling Weight Deflectometer Data, Transportation Research Record 1227, Transportation Research Board, Washington, 115-127 (1989)

[4] P. Kadar, The Performance of Overlay Treatment and Modified Binders Under Accelerated Full Scale Loading- The Callington ALF Trial, Australian Road Research Board, Victoria, (1990)

[5] J.R. Johnson-Clark, K.G. Sharp and P.D. Walter, The Performance of Pavements with Geotextile Reinforced Seals: The Brewarrina, N.S.W. ALF Trial, Research Report 241. Australian Road Research Board, Victoria, (1993)

[6] M.S. Tang, Medeiros and G.R. Chehab, Numerical modeling and laboratory testing of geogrid-reinforced flexible pavements, efficient transportation and pavement systems, Proceedings of the 4th International Gulf Conference on Roads, Doha, 10-13, (2008)

[7] I.L. Al Qadi, S.H. Dessouky and E. Tutumluer, Geogrid-reinforced low-volume flexible pavement response to loadings by various tire configurations. Efficient Transportation and Pavement Systems, Proceedings of the 4th International Gulf Conference on Roads, Doha, (2008)

[8] N. Ramadhan, and R.R. Burhanuddin, Effect of Gilsonite Additive on the Marshal Characteristics of Porous Pavement Mix, Thesis, Universitas Brawijaya, (2014)

[9] L. Djakfar, Harimurti and Y. Zaika, Preliminary assessment of the newly developed mobile accelerated pavement testing, Proceeding of the 9th International Conference on Road and Airfield Pavement Technology, Dalian, China, (10 - 12 August 2015) 